\title{
Design and Implementation of IoT- based Security System
}

\author{
Tarun Dhar Diwan, Avinash Kumar Tiwari, Sushil Kumar Kashyap
}

\begin{abstract}
In current circumstances, one of the biggest problems is the safety of women and assistance in medical field since women are scared of violence and sexual or physical assaults and abuses are increasing day by day leading women hesitating even to step out of their home. The major barrier in the progress of women present condition is the atrocities towards the women and this then leads to injustice between genders, here the value system supports this type of thinking or ideas that is insensitive toward genders as well as androcentric. In India the present scenario deals with thousands of cases of sexual or physical assaults and abuses that takes place even at a crowded place during day and especially at places that are backward or secluded women at night time can't move out. At the present situation of our country the crime that is growing fastest are rape cases along with other crimes. The system for security of women and medical assistance. Here presented a wireless method which will alert and communicate with the secure medium. Along with the audio records this can also store incidents that gets transmitted simultaneously sending the location of the person wearing this to the police. When the sensor kit button is pressed the mobile will record the incident this will store the user's information. Attached recording will also be transmitted to the phone number that is already registered with this data or information. With the help of the mechanism of GPS tracking. Medical assistance protection and women's monitoring will gain efficiency and speed with this data or information. On the phone number that is already registered alert messages with me sent. Due to this without any time loss the victim can receive the required help and this system help the user to save a large span of time.
\end{abstract}

Keywords: sensor, IoT, GPS, GSM, Google map, medical assistance, safety.

\section{INTRODUCTION}

In the present senior, because of the fear of sexual or physical assaults and abuses along with the fear of violence women cannot come out of their residence at any given time hence there is a major problem in women safety aspects[1]. The major barrier in the progress of women present condition is the atrocities towards the women and this then leads to injustice between genders, here the value system supports this type of thinking or ideas that is insensitive toward genders as well as androcentric[2]. As parts of the society which are oppressed in some or the other way by the so-called upper class or privileged once that further adds up to their struggles and inequality to get access to their rights

Revised Manuscript Received on April 25, 2020.

* Correspondence Author

Tarun Dhar Diwan*, Assistant Professor, Computer Science, Govt. E.R.R.P.G Science college, Chhattisgarh. tarunctech@gmail.com

Avinash kumar Tiwari, Assistant Professor, Computer Science, Govt. E.R.R.P.G Science college, Chhattisgarh.proffavinashktiwari@gmail.com

Sushil kumar kashyap, Assistant Professor, Information Technology, Rajeev Gandhi Govt. Science college, Ambikapur, Chhattisgarh. pmrsushil@gmail.com

(C) The Authors. Published by Blue Eyes Intelligence Engineering and Sciences Publication (BEIESP). This is an open access article under the CC BY-NC-ND license (http://creativecommons.org/licenses/by-nc-nd/4.0/) which is provided to them the democracy itself and simultaneously one can In India the present scenario deals with thousands of cases of sexual or physical assaults and abuses that takes place even at a crowded place during day and especially at places that are backward or secluded women at night time can't move out. At the present situation of our country the crime that is growing fastest are rape cases along with other crimes [3]. In India over a past few years one can observe some of the big differences in the social status of women. The history of India in different status of women has been eventful from social reformers emphasizing on women rights and equality moving back to the medieval time with low points further to the ancient period for equal status with the men.

\section{REVIEW CRITERIA}

For anyone that requires any kind of assistance in medical field or in any condition of urgency may it be any citizen, senior citizens or women Stay Safe Application can serve as a great safety application to them. With a little or even with the effort that is undetectable one can receive the help with the help of this application[4]. The expected emergence possibilities in the present society are:

1. When one is returning home from office they can be stalked.

2. At night one can be chased or stalked by a car.

3. At an area with no public attempts of harassments and assaults might take place.

4. Emergency while camping, hiking or picnic.

5. Burglaries attack at home.

In this presented research paper, there is an analysis review, on the difficulties to develop a system that overcomes all the requirements of technology along with the basic requirements of intelligence security system. With the help of this system anyone get an help of their family members and friends in an emergency situations [5]. This starts the assistance at the time of requirement and decreases the chances of risk. In this research paper we have discussed about a application that is triggering the security and introduced on an android platform. This also send the emergency contacts the condition linked images along with help signals this is something that makes it unique from other Safety applications [6].

\section{OBJECTIVE}

The objective of this research is security of women and Medical support related issues surrounding the internet of things. It presented a wireless method which will alert and communicate with the secure medium [7]. It will send police the wearer's location along with the record of audio and incident recording. 
- To study on women security and medical assistant-based literatures on IoT.

- To design intelligent security solution for women security and medical support solution for women based on IoT.

- To develop various algorithms related to various components of the proposed security framework.

- $\quad$ To generate emergency alert message for women safety and medical suffering persons with location tracking.

- To provide real time medical support system for IoT based health care services and applications.

To provide an efficient model for security issues by giving the chance to watch into the privacy and security problems that revolves around Healthcare solutions of IoT.

\section{METHODOLOGY}

The methodology used in this research paper, the Gadget for alerting just by pressing the given button emergency alerting button (SOS) this device can be made active [8]. This gadget based on IoT that gets activated, which retrieves its accurate place with the help of latitude and longitude, that includes GPS modem, to the microcontroller the data is feed that from the GSM retrieves the details of the required place and this also triggers the wristband [9]. The wristband also triggers the mobile application will receive information form a chip that send a message along with the instant device location with the help of this chip that is present in the women wearable gadget and the message that is sent is like "Save me, I'm in danger" to her family, friends, a group or to the police station[10].

Internet of Things (IoT) The Internet of Things (IoT) refers to the network of devices that are accessible through internet connectivity and the communication that occurs between these devices and other Internet-enabled devices and systems. IOT is expected to offer advanced connectivity of devices, systems, and services that goes beyond machine-to-machine (M2M) communications and covers a variety of protocols, domains, and applications [11].

\section{Mechanisms For Detecting Locaton}

\section{System Algorithm}

Step 1: Women register in the system.

Step 2: Women login in the System.

Step 3: Women wear the smart band.

Step 4: Wearable device contain pulse rate Sensor and temperature sensor.

Step 5: Every 10sec. value will be compared with the training dataset.

Step 6: If any abnormal values is encountered then system send alert message on device. Step 7: If she doesn't reply in given time about awareness.

Step 8: System track the current location of women. Step 9: Emergency message send to family member, friend and nearby police station with her GPS location.

Step 10: Also send message any user whose location is near by the victim.

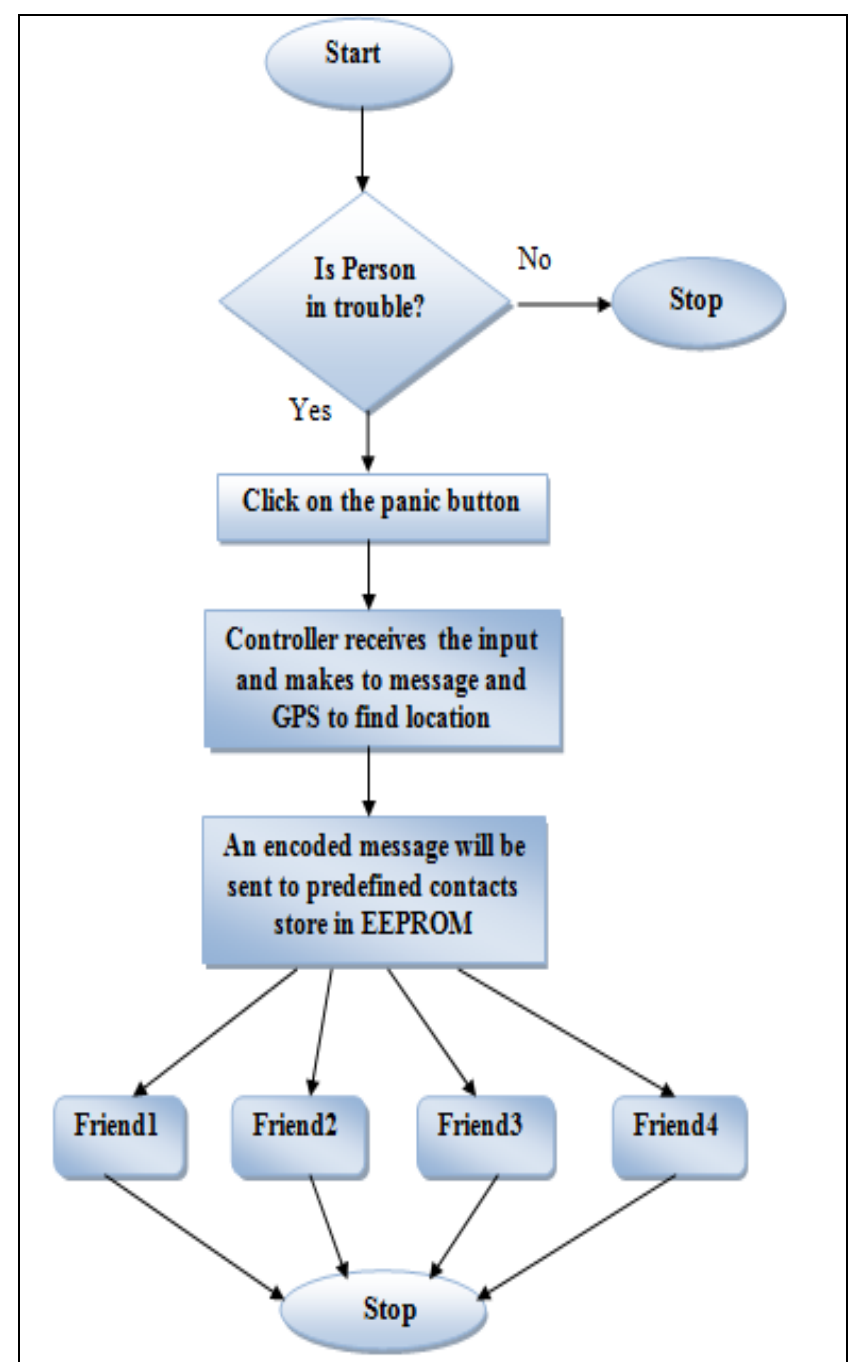

Fig.1: Flow chart of security system.

\section{RESULT AND DISCUSSION}

The comparison table for different persons can detect physical property, it will indicate, record, responds to it, mainly sensors are used to detect the changes in the environment that may be physical parameters, heartbeat temperature and sound [12].

Sensors are used: -Alert message, abnormal sound, heartbeat, temperature, sensors are used.

The key objective of this research paper focuses to serve the users with the security system that includes services like SMS services, location-based services, system architecture and GPS services [13]. Learning of much latest skills that varies from working with the latest technologies and some of the important team work experiences, these all learnings were acquired while working on the research first phase. Few of the vital modules that comprises registration modules in this application the id and password is registered by the user and then this id and password is used afterwards for login the modules. Many uses are possible with the help of the one activates button this is provided in the next module [14]. Data service and silent mode are enabled using this activate button. All modules are cover in the last phase of this research paper.

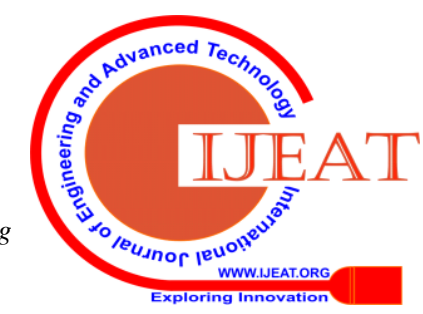


Table- I: Table on the bases of different Women

\begin{tabular}{|l|l|l|l|l|}
\hline $\begin{array}{l}\text { PEOPLE IN } \\
\text { TROUBLE }\end{array}$ & $\begin{array}{l}\text { HEART } \\
\text { BEAT } \\
\text { SENSOR }\end{array}$ & $\begin{array}{l}\text { MESSAGE ALERT } \\
\text { TYPE }\end{array}$ & $\begin{array}{l}\text { TEMPERATU } \\
\text { RE SENSOR }\end{array}$ & $\begin{array}{l}\text { MESSAGE ALERT } \\
\text { TYPE }\end{array}$ \\
\hline P1 & 72 & NORMAL & 37 & NORMAL \\
\hline P2 & 74 & EMERGENCY & 37.5 & NORMAL \\
\hline P3 & 72 & NORMAL & 36.8 & NORMAL \\
\hline P4 & 73 & NORMAL & 39.6 & EMERGENCY \\
\hline P5 & 79 & EMERGENCY & 37.3 & NORMAL \\
\hline P6 & 80 & EMERGENCY & 39.8 & EMERGENCY \\
\hline P7 & 72 & NORMAL & 38.6 & NORMAL \\
\hline P8 & 72 & NORMAL & 38.7 & NORMAL \\
\hline P9 & 71 & NORMAL & 36.6 & NORMAL \\
\hline P10 & 81 & EMERGENCY & 41 & EMERGENCY \\
\hline
\end{tabular}

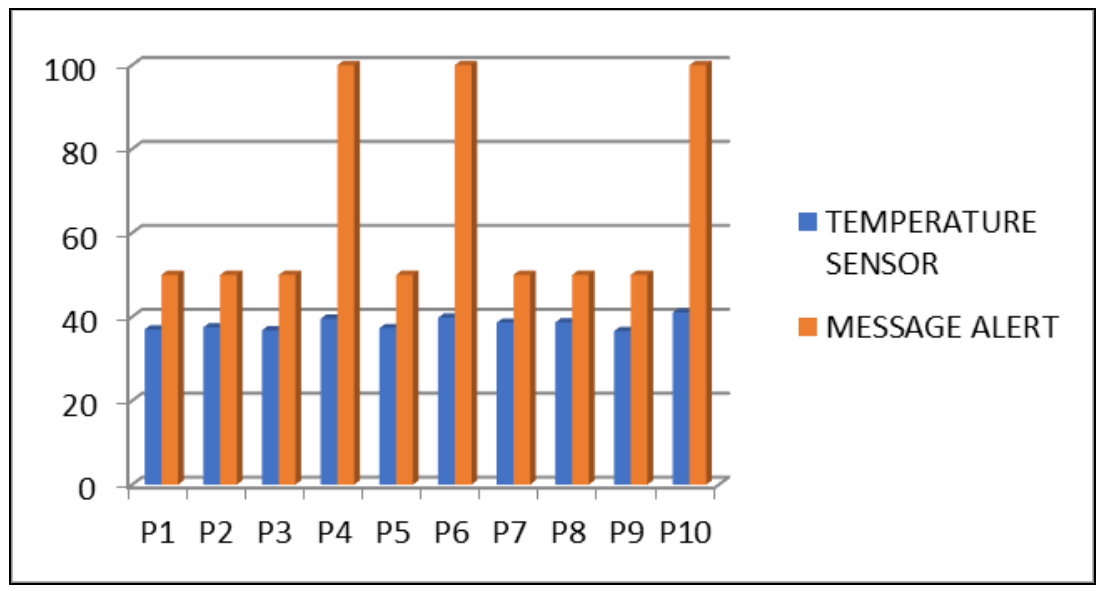

Fig.2: A temperature is increase then message system alert.

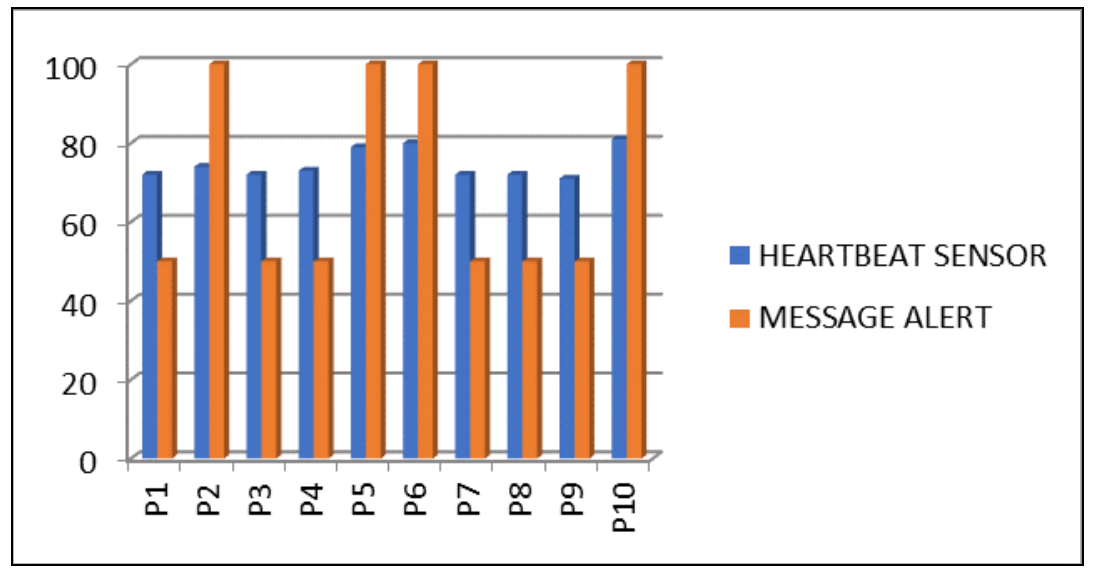

Fig.3: A heartbeat is increase then message system alert.

Here the option served by us, one of them helps to add any five contacts for emergency situations by the user and another one is to change or update this list at any given point of time [15]. Along with this we have worked on a text message box that has one emergency text message and this also provides those emergency contacts with the link to GPS location that has latitude and longitude. In addition to all this [16]. we have also added a feature to send a situation related image. With all these features at last we say that with the help of this application in some of the cases can be served with a useful proof of the situation. This application focuses mainly on girl's safe issues that is name as "Stay Safe App". For many emergency conditions for example if some girl is travelling along, she can use this application for her protection and safety purposes. This will help the girl to send family, friends and police stations her current location with a single click. To

Retrieval Number: D9076049420/2020@BEIESP

DOI: 10.35940/ijeat.D9076.049420

Journal Website: www.ijeat.org the person added to the list this application will continuously sends the messages regarding her updating location. Hence, we can conclude that this application fulfills the two criteria of security and safety that requires the code of conduct based on engineering that is very important in present scenario [17]. This research proposed the system for security of women. It presented a wireless method which will Salter and communicate with the secure medium. This application sends the emergency contact the wearer's location along with the recording of the situation this recording is an audio record. From above survey, we can analyze that GSM, GPS and sensors has the ability to transmit the nearby location or placement of the user and send the limited people the alert messages.

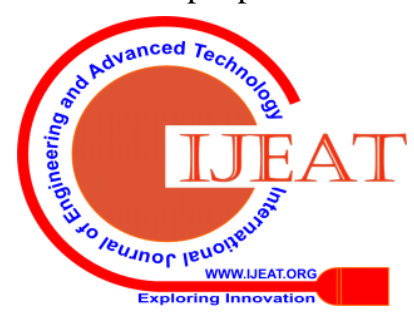


When the user is in emergency situations there is a buzzer in this application or system that alerts the emergency numbers, the security of women is looked after by send alert SMS to the emergency numbers by this application. The current location of the user is share with the transmitted text emergency message sent with the help of SOS[18]. A new invention or way is required that sends the text emergency message directly without any human efforts. With the help of more parameters based on physical human body the precision level of the application to detect the violence against a woman can be enhanced. Whereas the sensor kit button is pressed the mobile will record the incident also detail of the user is collected [19]. This information as well as the audio records will be sent or transmitted to the emergency numbers. With the help of a mechanism called GPS tracking the application can speed monitor the women's security level. This is the "Women security system using GPS and GSM". for safety of many girls this is a useful application whenever there is any situation of emergency for an example if we are stuck in a situation we are using cab at late night for travelling from office to home we can easily use this app without any fear as one can send their family, friends and police stations their current location within a single click[20]. During transmission of a text message and current location along with this an audio record is also sent to the emergency phone numbers [21].

\section{CONCLUSION}

This application can be a great relief to the women of the country for their security and safety purposes. The application that send online as well as offline SMS to particular emergency contact number. to the registered emergency phone numbers, the alert messages will be sent. This helps the user greatly without any time loss. The key objective of this research paper focuses to serve the users with the security system that includes services like SMS services, location-based services, system architecture and GPS services. Learning of much latest skills that varies from working with the latest technologies and some of the important team work experiences, these all learnings were acquired while working on the research first phase. Few of the vital modules that comprises registration modules in this application the id and password is registered by the user and then this id and password is used afterwards for login the modules. Many uses are possible with the help of the one activates button this is provided in the next module. Data service and silent mode are enabled using this activate button. All modules are cover in the last phase of this research paper. Here the option served by us, one of them helps to add any five contacts for emergency situations by the user and another one is to change or update this list at any given point of time. Along with this we have worked on a text message box that has one emergency text message and this also provides those emergency contacts with the link to GPS location that has latitude and longitude. In addition to all this we have also added a feature to send a situation related image. With all these features at last we say that with the help of this application in some of the cases can be served with a useful proof of the situation. This application focuses mainly on girl's safe issues that is name as "Stay Safe App". For many emergency conditions for example if some girl is travelling along, she can use this application for her protection and safety purposes. This will help the girl to send family, friends and police stations her current location with a single click. To the person added to the list this application will continuously sends the messages regarding her updating location. Hence, we can conclude that this application fulfills the two criteria of security and safety that requires the code of conduct based on engineering that is very important in present scenario.

New version is required to be developed as the technology advances or future new requirements of the user comes up that demands new features to improve the present technology. We can see that this system works efficiently and is complete, without much changed to the present system new modules can be added to improve the system efficiency and functionality further. When some of the modules that were not able to be added in the last system because of the limited time such modules can be identified amongst the various other modules. Therefore, system is made dependable and robust by adding advanced technologies.

\section{FUTURE WORK}

The safety is improved as more functionalities are offered by the newer modules. When the user is traveling or in any type of an emergency situations this application is very helpful. 1 From the wristband removing GPS and GSM modules there can be a future reduction in the size of the wristband. To gain access to the needed service the GPS and GSM modules on the phone could be used. This will be useful for the user to hide this device from the attacker and gives an easy access to the user.

2. This device can be provided with an inbuilt solar cell that will help the band with the extra power and life, this will help greatly to increase the battery life of the wearable gadget. When this can be achieved the user can wear this device the complete day without any problem of battery change or exhaustion.

3. We can take the help of XMPP and GCM to get an unique ID this can be of great use to increase the security by hiding or concealing the true identity of the user or victim and this will deliverer the message with the help of packet data network hence this will also help to hide or conceal the users true ID.

4. A miniature camera can be fixed on the wristband to record the situation this will help the victim with the better proofs against the crime and also to gain better proofs against the criminal.

\section{REFERENCES}

1. Tarun Dhar Diwan, Upasana Sinha "The Machine Learning Method Regarding Efficient Soft Computing and ICT Using SVM" international journal of computer engineering \& technology (ijcet), issn 0976 - 6367(print) issn 0976 - 6375(online) volume 4, issue 1 , january- february (2013), pp. 124-130.

2. Tarun dhar diwan,upasana Sinha,siddhartha choubey," A Novel Technique on Detect Melanoma in Dermoscopy Images By using Deep Learning" International Journal of Innovative Technology and Exploring Engineering (IJITEE) ISSN: 2278-3075, Volume-9 Issue-3, January 2020.

3. Tarun Dhar Diwan,Upasana Sinha" performance analysis is basis on color based image retrieval technique" international journal of computer engineering \& technology (ijcet) issn 0976 - 6367(print) issn 0976 - 6375(online) volume 4, issue 1, january- february (2013), pp. $131-140$.

Blue Eyes Intelligence Engineering \& Sciences Publication 
4. Simon L. Cotton and William G. Scanlon, "Millimeter - wave Soldier tosoldier communications for covert battlefield operation," IEEE communication Magazine, October 2009.

5. Alexandrous Plantelopoulous and Nikolaos.G.Bourbakis, "A Survey on Wearable sensor based system for health monitoring and prognosis," IEEE Transaction on system, Man and Cybernetics, Vol.40, No.1, January 2010.

6. B.Chougula, "Smart girls security system," International Journal of Application or Innovation in Engineering \& Management, Volume 3, Issue 4, April 2014

7. Palve Pramod, "GPS Based Advanced Soldier Tracking With Emergency Messages \& Communication System," International Journal of Advance Research in Computer Science and Management Studies Research Article, Volume 2, Issue 6, June 2014.

8. AntoBennet, M \&JacobRaglend, "Performance Analysis of Block Artifact Reduction Scheme Using Pseudo Random Noise Mask Filtering", European Journal of Scientific Research, vol. 66 no.1, pp.120-129, 2011.

9. A.H.Ansari, BalsarfPratiksha P, MaghadeTejal R, YelmameSnehal M, "Women Security System using GSM \& GPS", International Journal of Innovative Research in Science, Engineering and Technology", Vol.6, Issue 3, March 2017.

10. Azhaguramyaa V R, Sangamithra D, Sindhja B, "RFID Based Security System for Women”, International Journal of Scientific \& Engineering Research Volume 8 Issue 5, May-2017.

11. TruptiRajendraShimpi, "Tracking and Security System for Women's using GPS \& GSM, International Research Journal of Engineering and Technology (IRJET), Volume: 04 Issue:07 | July-2017.

12. S. Vahini, N. Vijaykumar, "Efficient tracking for women safety and security using IoT", International Journal of Advanced Research in Computer Science, Volume 8, No,.9, November-December 2017.

13. D.G. Monisha, M. Monisha, G. Pavithra and R. Subhashini, "Women Safety Device and Application-FEMME", Indian Journal of Science and Technology, Vol9 (10), March 2016.

14. GeethaPratyushaMiriyala, P.V.V.N.D.P Sunil, RamyaSreeYadlapalli, Vasantha Rama Lakshmi Pasam, TejawiKondapalli, AnushaMiriyala, "Smart Intelligent Security System for Women", International Journal of Electronics and Communication Engineering \& Technology (IJECET), Volume 7, Issue 2, March-April 2016.

15. RashaTalal Hammed, Omar AbdulwahabeMohamad, NicolaeTapus, "Health Monitoring System Based on Wearable Sensors and Cloud Platform", 20th International Conference on System Theory, Control and Computing (ICTSCC), 2016.

16. AbhijitParadkar, Deepak Sharma, "All in one Intelligent Safety System for Women Security", International Journal of Computer Applications (0975-8887) Volume 130- No.11, November 2015.

17. Rajesh, M., and J. M. Gnanasekar. "Path Observation Based Physical Routing Protocol for Wireless Ad Hoc Networks." Wireless Personal Communications 97.1 (2017): 1267-1289.

18. Rajesh, M., and J. M. Gnanasekar. "Sector Routing Protocol (SRP) in Ad-hoc Networks." Control Network and Complex Systems 5.7 (2015): 1-4. 19. Rajesh, M. "A Review on Excellence Analysis of Relationship Spur Advance in Wireless Ad Hoc Networks." International Journal of Pure and Applied Mathematics 118.9 (2018): 407-412.

19. 20.Rajesh, M. "A signature-based information security system for vitality proficient information accumulation in wireless sensor systems." International Journal of Pure and Applied Mathematics 118.9 (2018): 367-387.

20. Rajesh, M., K. Balasubramaniaswamy, and S. Aravindh. "MEBCK from Web using NLP Techniques." Computer Engineering and Intelligent Systems 6.8: 24-26.

\section{AUTHORS PROFILE}

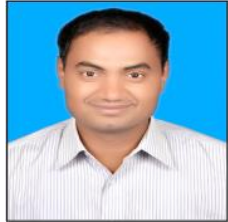

Prof. Tarun Dhar Diwan He is an Asst. Prof. at the Govt. E.R.R Post Graduate Science College, India and holds a M. Tech, M.Phi,..in Computer Science and Engineering from the CSVTU in 2012, Bhilai, India. Pursuing P.hd. from the same university. His Research interest Include Artificial Intelligent, Computer Network and Security, Machine Learning,

Internet of Things.

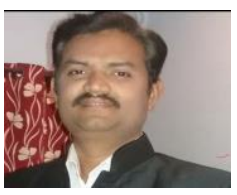

Prof. Avinash kumar Tiwari, Govt. E.R.R Pos Graduate Science College, India and holds a $\mathrm{M}$. Tech, in Computer Science and Engineering, Pursuing P.hd.. His Research interest Include Artificial Intelligent, Computer Network and Security.

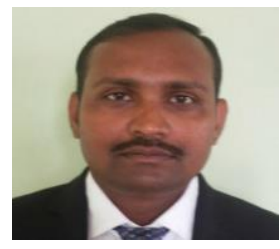

Prof. sushil kumar Kashyap, $\mathrm{He}$ is an Asst. Prof. at the Govt. Science College,ambikapur India and holds a M.Sc, M.Phi,..in Information Technology from the Dr. C.V.Raman University, Bilaspur, India. Pursuing P.hd. from the same university. His Research interest Include Artificial Intelligent, Computer Network and

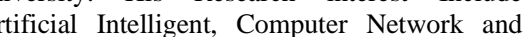

Security,

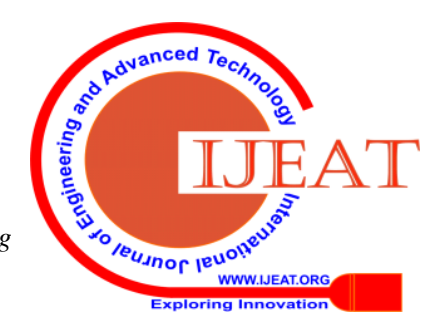

